\title{
A Perspective Model for Borehole Thermal Resistance Prediction of a Vertical U-Tube in Geothermal Heat Source
}

\begin{abstract}
By Ali H. Tarrad
The present work describes a mathematical model to postulate a short cut method for the preliminary thermal design of a ground single U-tube heat exchanger. A one-dimensional steady state heat transfer mode was assumed to derive a correlation for the borehole thermal resistance to heat transfer process. The model has considered the transformation of the U-tube system into a concentric single equivalent straight tube. Its diameter was estimated from the mutual interaction between fixed volume and fixed surface area models for the treatment of U-tube and equivalent tube geometry configurations. Three Copper single U-tubes of outside diameters, $12.7 \mathrm{~mm}, 15.88 \mathrm{~mm}$ and $19.05 \mathrm{~mm}$ with tube spacing of $42 \mathrm{~mm}, 55.6 \mathrm{~mm}$ and $67 \mathrm{~mm}$ respectively were utilized to build the heat exchangers. These borehole geometry configurations were investigated as direct exchange condensers circulating $R-410 A$ at a grout thermal conductivity range of (0.73-1.9) W/m.K. The results showed that the filling thermal conductivity has a vital role in the borehole thermal performance and heat transfer rate to or from the ground source. The specific total thermal resistance of the investigated configurations was halved when the grout thermal conductivity was increased from $0.73 \mathrm{~W} / \mathrm{m} . \mathrm{K}$ to $1.9 \mathrm{~W} / \mathrm{m} . \mathrm{K}$. The present correlation was compared with other published models in the open literature and showed an excellent agreement.
\end{abstract}

Keywords: Borehole Thermal Resistance, Vertical U-tube Modeling, Correlation, Geothermal DX Condensers, R-410A

\section{Introduction}

Geothermal energy source is conceived as a clean, cheap and sustainable form of other renewable energy sources. It has been implemented for a long time perhaps since the forties of the last century for heating and cooling purposes. The most important component of any geothermal heat pump system is represented by the ground heat exchanger (GHE) to reject or absorb energy from the ground. Hence, a tremendous work and effort have been spent to understand and optimize the (GHE) design and sizing to reveal the best performance in regards of amount of energy transferred and installation cost. The latter is affected by the criteria of meteorological properties, geometrical attributes of heat exchanger in the borehole, tubing characteristics and grout's thermal conductivity.

Modeling of such heat transfer problem is considered as a complex issue to be handled and represented mathematically. However, there is quite a good number

*Professor, University of Lorraine, France. 
of research work has been accomplished in the field of modeling the (GHE) analytically, numerically and experimentally, Kavanaugh (1985), Zeng et al. (2003). The main design objectives were focused on the thermal resistance of the grout surrounding the U-tubing and heat transfer rate to or from the ground source. The analytical models for (GHE) utilize mainly a line heat source in Ingersoll et al. (1948) and Muttil and Chau (2006) and cylinder heat source theory in Ingersoll et al. (1954) and Carslaw and Jaeger (1959) to predict the heat transfer rate between the ground and the heat carrier fluid flowing in the (GHE).

Garbai and Méhes (2008) proposed a model to calculate the temperature change and the thermal resistance in vertical ground heat exchangers with single U-tube installation. They predicted the amount of extractable heat from the U-tube as a function of fluid mass flow rate passing through the ground tubing. Hafiz et al. (2017) have rated numerically an existing (60) kW heat pump system in Finland with a ground source of (250) $\mathrm{m}$ borehole heat exchanger depth. They estimated an optimal length for the heat capacity of the heat pump to enhance the performance of the system. A transient thermal performance of a vertical double U-tube borehole heat exchanger was numerically studied by Zhu et al. (2019). They examined a ground heat exchanger at water velocity range of $0.1 \mathrm{~m} / \mathrm{s}$ and 0.5 $\mathrm{m} / \mathrm{s}$. They concluded that the charging temperature had a more vital influence than the flow velocity on soil temperature lifting. A value of $0.3 \mathrm{~m} / \mathrm{s}$ for water velocity in a borehole depth of $55 \mathrm{~m}$ was recommended.

Sharqawy et al. (2009) developed a 2-dimensional numerical model for the steady-state heat conduction between the U-tube and borehole configuration. They suggested a correlation for the borehole thermal resistance in the form:

$$
R_{f}=\frac{\left(-1.49 \frac{S_{p}}{D_{B}}+0.656 \ln \left(\frac{D_{B}}{d_{0}}\right)+0.436\right)}{2 \pi k_{g}}
$$

They took into account the tube spacing inside the borehole in the correlation formulation, it was claimed that their correlation predicted the thermal resistance better than other available formulas.

The equivalent diameter technique has been implemented by a number of investigators to represent the U-tube heat exchanger for mathematical and geometrical treatment. The equivalent diameter of U-tube can be presented in the form of:

$d_{e}=\beta d_{0}$

Where $(\beta)$ is a constant greater than 1. Bose et al. (1985) presented the grout thermal resistance in the form:

$$
R_{f}=\frac{\ln \left(\frac{D_{B}}{\sqrt{n} d_{0}}\right)}{2 \pi k_{g}}
$$

In which the equivalent diameter corresponds to: 
$d_{e}=\sqrt{n} d_{0}$

Where (n) is equal to 2 for a single U-tube system. The U-tube pipes were modeled as a single pipe in the center of the bore with an equivalent radius accounted for the same cross sectional area of heat exchange. The heat conduction between the thin film, filling material and ground was calculated in the radial direction. Gu and O'Neal (1998) utilized a steady-state heat transfer simulation based on the cylindrical source model. They presented the equivalent diameter in a formula that coupled the tube diameter and the leg spacing in the form:

$R_{f}=\frac{\ln \left(\frac{D_{B}}{d_{0}} \sqrt{\frac{d_{o}}{S_{p}}}\right)}{2 \pi k_{g}}$

Rearranging this equation reveals that the equivalent diameter was expressed as:

$d_{e}=\sqrt{S_{p} d_{o}}$

They postulated a range of $(\sqrt{2}-2 \sqrt{2})$ for the coefficient $(\beta)$ in eq. (2) depending on the U-tube legs spacing in the range of (1-4) times the outside tube diameter. Remund (1999) presented a correlation to predict the borehole thermal resistance for the three configurations of GHE pipes, close together, average and along outer wall of the borehole. The expression for the case of average tubes condition that investigated in this work was formulated as:

$R_{f}=\frac{1}{17.44 k_{g}\left(\frac{D_{B}}{d_{0}}\right)^{-0.6052}}$

Claesson and Dunand (1983) has derived analytically the value of $(\beta)$ for two buried horizontal pipes to be $\sqrt{2}$. Thus, this value shows an effective equivalent diameter corresponds to the summation of cross sectional area of both tubes. Mei and Baxter (1986) concluded that the value of the coefficient varies from well to another for their experiments. It has a scatter between 1.0 and 1.662 with a mean value of 1.28 , this was smaller than the $\sqrt{2}$ calculated by Claesson and Dunand and 1.84 by Fischer and Stickford (1983). The significant impact of the value of $(\beta)$ is directly related to the contact surface area of heat exchanger and effective volume of the backfill. Both of these factors are coupled to reflect the heat transfer rate for heating and cooling purposes at the ground heat exchanger (GHE). More recently, Tarrad (2019) has established a correlation to estimate the total borehole thermal resistance. He replaced the U-tube geometry with a concentric equivalent tube having the same resistance as that of the original U-tubing in the form:

$d_{e}=\frac{D_{B}}{\left(x+\sqrt{x^{2}-1}\right)}$ 
In this mathematical expression:

$x=\frac{D_{B}{ }^{2}+d_{0}{ }^{2}-S_{p}{ }^{2}}{2 D_{B} d_{0}}$

Hence, the thermal resistance of the grout was represented as:

$R_{f}=\frac{\ln \left(\frac{v_{B}}{d_{g}}\right)}{2 \pi k_{g}}$

\section{Present Model}

\section{Equivalent Diameter}

The model is based on the idea of substitution of the $\mathrm{U}$ tubing by a single tube having a close operation conditions as possible to the original U-tube as shown in Figure 1.

Figure 1a. Ground U-tubing

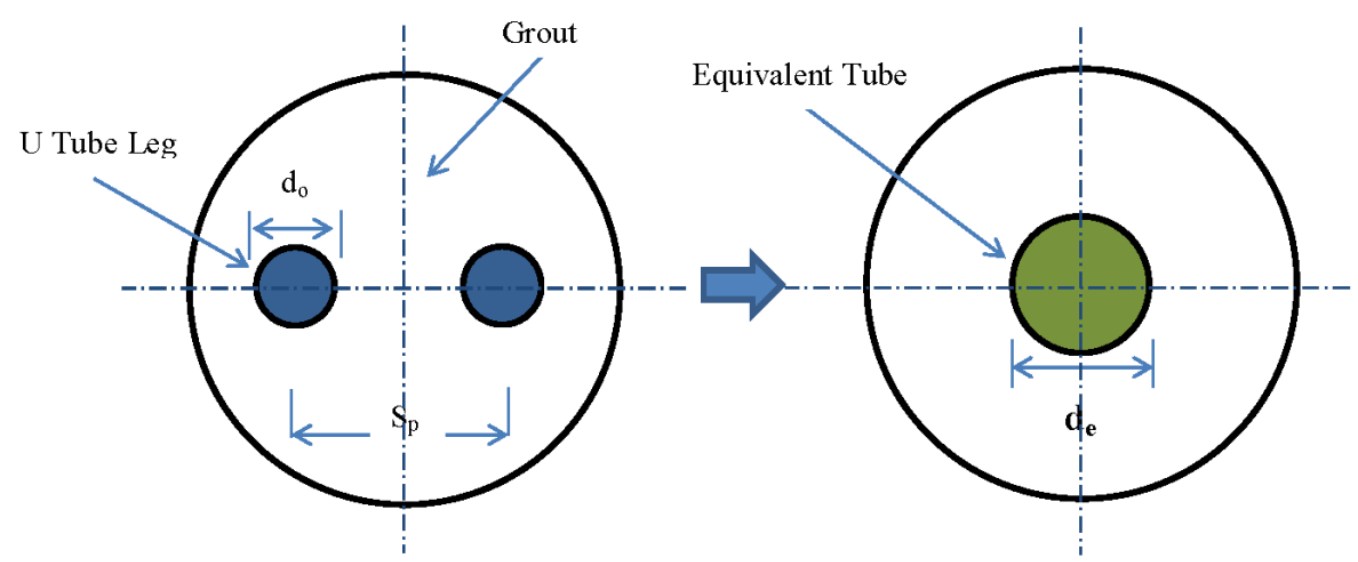

Figure 1b. Single Tube Heat Exchanger

The equivalent diameter of the single tube is a complicated matter especially when dealing with physical presentation of contact surface area, volume of the filling, and conductance of different factors of heat transfer domains of the borehole geometry. This dialogue leads to the interpretation presented in this work; hence, the equivalent diameter of the $U$ tubing is sought to provide a sort of compromise for both conditions.

The volume of the backfill in the borehole has its effect on the heat transfer rate during the transient unsteady state conditions. Gabrai and Méhes (2008) concluded that the operation of the ground U-tube heat exchanger approaches a steady state conditions after one year of its operation. If the U-tubing has similar diameters for both legs and assuming a constant volume of the grout for both geometries of U-tube and equivalent one; then: 
This equation yields:

$d_{e}=\sqrt{2} d_{0}$

This result is similar to that of Bose et al. (1985) and Claesson and Dunand (1983) as illustrated in eq. (3).

The mathematical presentation should be as close as possible to the original geometrical configuration of the borehole. The surface area of the U-tube, tube wall and filling thermal resistances control the heat transfer process for fixed borehole diameter under steady state conditions. When the contact surface area is considered constant for both geometries, then we have the following relation:

$2 \pi d_{0} L=\pi d_{\theta} L$

Hence

$d_{e}=2 d_{0}$

The value of $(\beta)$ in eq. (2) becomes 2 and this is within the range of the coefficient postulated by Gu and O'Neal (1998) in eq. (4). Now let us consider the mean value of eqs. (8.b) and (9.b) which reveals the value of $\left(d_{e}\right)$ of the equivalent diameter for the suggested geometry in the form:

$d_{e}=\frac{\sqrt{2} d_{0}+2 d_{0}}{2} \approx \sqrt{3} d_{0}$

Similarly, for the case when the U-tube composes of different legs sizes which are the usual geometry considered for condensers and evaporator. The vapor phase passes through a leg of bigger diameter than that of the liquid phase for hydrodynamic reasons. The following relation still holds in the form of:

$d_{e}=\frac{\sqrt{d_{1}{ }^{2}+d_{2}{ }^{2}}+\left(d_{1}+d_{2}\right)}{2}$

In eq. (11), the equivalent diameter of the U-tube shows the same expression as that of eq. (10) when the U-tube composes of the similar tube diameter for both legs. The heat transfer rate to or from the ground source through the heat exchanger may be mathematically presented as:

$$
\begin{aligned}
& \dot{Q}_{U-t u b_{e}}=U_{U-t u b_{e}} A_{U-t u b_{e}} \Delta T_{m}=\frac{P_{U-t u b_{e}} \Delta T_{m}}{\sum R_{U-t u b e}} \\
& \dot{Q}_{e}=U_{e} A_{e} \Delta T_{m}=\frac{P_{e} \Delta T_{m}}{\sum R_{\theta_{e}}}
\end{aligned}
$$

Where 
$\sum R_{U-\text { tube }}=R_{\text {conv }}+R_{\text {cond }, p}+R_{\text {grout }}+R_{\text {ground }}$
$\sum R_{e}=R_{\text {conv }}+R_{\text {cond }, p}+R_{\text {e, grout }}+R_{\text {ground }}$

The mean temperature difference $\left(\Delta T_{m}\right)$ is defined as:

$\Delta T_{m}=T_{\text {fluid, } m}-T_{\text {ground }}$

and

$T_{\text {fluid, } m}=\frac{T_{\text {fluid, in }}+T_{\text {fluid, out }}}{2}$

The present model expression will minimize the effect of transformation of the U-tube to a single equivalent one on the contact surface area for the (GHE). The mean value will be used for the present work as an equivalent diameter to predict the single tube transformed geometry shown in Figure 1b. Claesson and Dunand (1983) concluded that the value of the coefficient $(\beta)$ must be $(<2)$. Whereas, Gu and O'Neal (1998) in their analytical work showed higher values as high as 2.8 .

The present work stated different equivalent diameter expression than those of Bose et al. (1985) and Gu and O'Neal (1998). The latter predicts similar grout thermal resistance to that of Bose et al. (1985) when the tube spacing is selected as $\left(2 \mathrm{~d}_{\mathrm{o}}\right)$. Further the $\mathrm{Gu}$ and O'Neal predicts the same grout thermal resistance as that of the present work when the tube spacing is selected as $\left(3 d_{o}\right)$. The tube spacing lies in the range of recommended bending radius $r_{b e n d}=(2-3) d_{o}$ for the purpose of fabrication of the copper tubes, Copper Development Association Inc. (2019). In other words, the effect of tube spacing on the equivalent diameter has been dropped out by selecting a proper geometrical configuration. This criterion for geometry layout is suitable for heat pumps that utilize the (DX) ground heat exchangers since it simplifies the fabrication of the U-tube. Further, for condensers or evaporators, which operate under isothermal process conditions, the mutual effect of heat conduction between the legs of U-tube through the shunt approaches zero. This criterion provides a flexibility to control the borehole geometrical configuration to minimize the influence of U-tube spacing on the grout thermal resistance.

The value of $(\beta)$ in this work corresponds to 1.732 as shown in eq. (10). This value is consistent with the condition stated in eq. (2), in which $(\beta)$ is greater than 1. It is satisfies the condition that revealed by Gu and O'Neal (1998), a value of (1.4-2.8) was assigned for $(\beta)$. It is also fulfill the stated condition by Claesson and Dunand (1983) who have concluded that the value of the coefficient $(\beta)$ must be $(<2)$. Further, the present value of the coefficient $(\beta)$ is close to the experimental value of Mei and Baxter (1986); it has a scatter between 1.0 and 1.662. 


\section{Pipe Thermal Resistance}

The thermal resistance of the pipe composes of convection inside the tube produced by the refrigerant flowing inside the ground heat exchanger and Utubing wall resistance due to conduction. The pipe thermal resistance of the U-tube is replaced by a conductance layer at the tube wall with the same significant impact as the original system. Hence, the equivalent tube will act as a lumped body, which possesses those resistances and exposed to the conditions of the grout or filling resistance presented in Figure 1b. For the tube resistance $\left(R_{p}\right)$, the general form of resistance analogy to the electric circuit in series defined as follows:

$R_{p}=\frac{1}{\pi d_{i} h}+\frac{\ln \left(\frac{d_{o}}{d_{i}}\right)}{2 \pi k_{p}}$

The pipe thermal resistance will be implemented for the equivalent geometry for the estimation of total thermal resistance of the borehole geometry. However, this resistance has no significant influence for the case where there is evaporation or condensation in a DX buried heat exchanger for heating and cooling modes in winter and summer respectively. The evaporation and condensation heat transfer coefficient are so high when compared with that of the brines used for the indirect geothermal systems. The thermal conductivity of ground tubing is also high, copper tube is usually used for direct geothermal heat exchangers with about 400 $\mathrm{W} / \mathrm{m}$. ${ }^{\circ} \mathrm{C}$. Hence, this resistance has no significant impact on the heat transfer rate through the filling around the tube for both modes.

\section{Shunt Resistance}

The legs of the U-tube transfer heat in the direction of higher to lower legs temperature levels. The thermal shunt resistance $\left(R_{S}\right)$ is modeled as isothermal pipe-to-pipe conduction shape factor in an infinite medium per unit length Holman (2010) as:

$$
\begin{aligned}
& S_{s}=\frac{2 \pi}{\cosh ^{-1}\left\{2\left(\frac{S_{p}}{d_{0}}\right)^{2}-1\right\}} \\
& R_{s}=\frac{1}{S_{s} k_{g}}=\frac{\cosh ^{-1}\left\{2\left(\frac{S_{p}}{d_{0}}\right)^{2}-1\right\}}{2 \pi k_{g}}
\end{aligned}
$$

For condensation and evaporation processes inside the U-tube, the mean temperature difference of the fluid between both legs tends to be zero. This phenomenon is usually assigned for the thermal process where change of phase takes place such as boiling and condensation of pure fluid. It may also be assumed for the case where there is a non-azeotrop mixture or azeotrop mixture having a negligible temperature glide such as $(R-410 A)$ refrigerant. Hence, the heat transfer rate in the shunt zone $\left(\dot{Q}_{S}\right)$ between the two legs of the U-tube tends to zero too. 


\section{Filling Thermal Resistance}

The single tube equivalent diameter will only be used for the calculation of thermal resistance of the filling. This resistance could be expressed from heat conduction in a composite cylindrical surface presented as:

$R_{f}=\frac{\ln \left(\frac{v_{B}}{d_{g}}\right)}{2 \pi k_{g}}$

Table 1 illustrates a comparison for the grout thermal resistance expressions and magnitudes of $(\beta)$ for various correlations.

Table 1. Correlations of Grout Thermal Resistance for a Single U-tube and Values of the Coefficient ( $\beta$ ) for Various Expressions

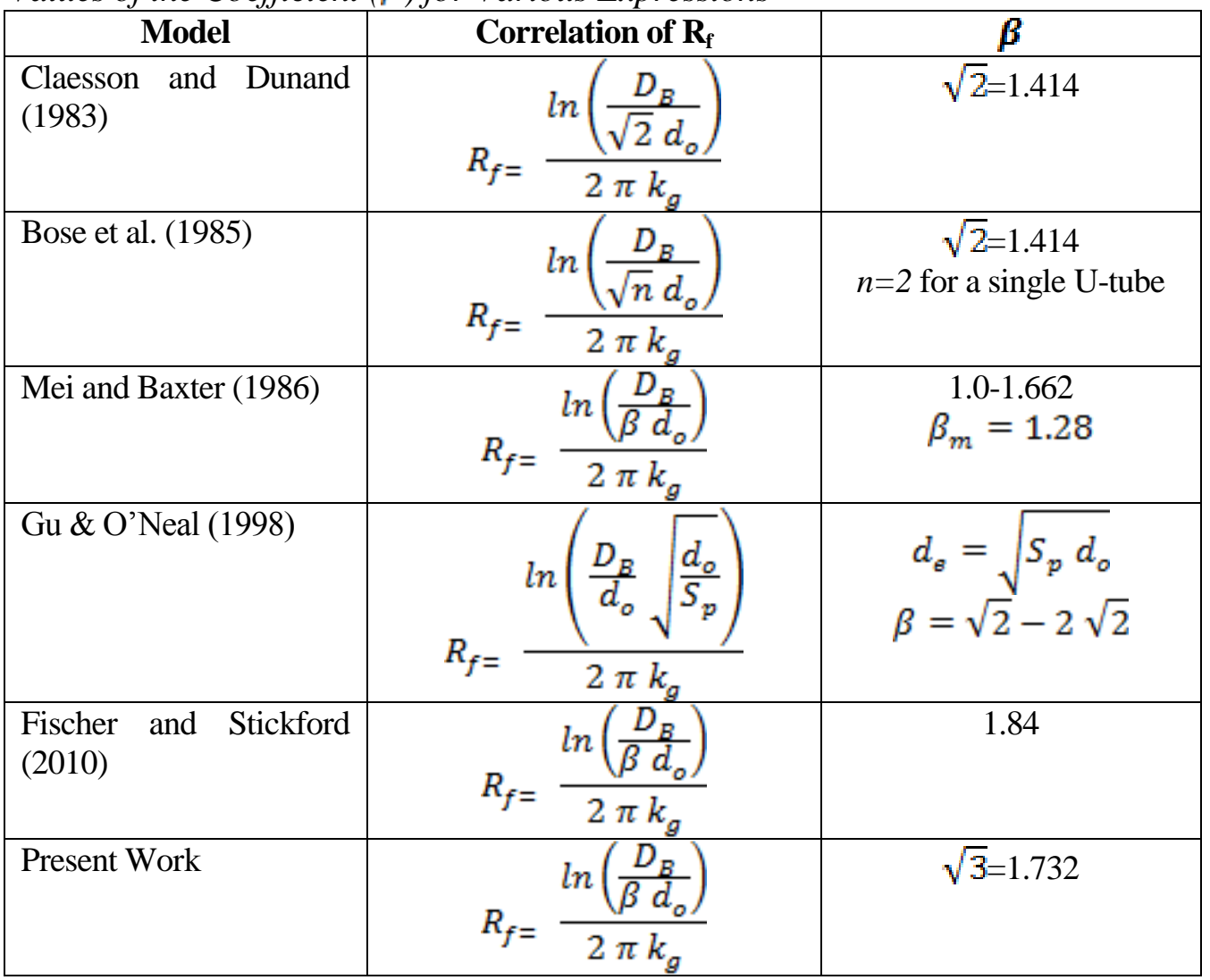

\section{Ground Thermal Resistance}

The thermal resistance of soil to heat transfer may also be considered here. Garbai and Méhes (2008) has included the effect of ground as a resistance to heat transfer from or to the U-tube fluid for a region extended to infinity. They have concluded that after one year of operation, the heat transfer process through the ground heat exchanger can be defined as a steady state heat flow condition. Their work revealed that the ground thermal resistance reached a steady state value of 
$0.053 \mathrm{~m} .{ }^{\circ} \mathrm{C} / \mathrm{W}$ for a ground thermal conductivity of $2.42 \mathrm{~W} / \mathrm{m} .{ }^{\circ} \mathrm{C}$. Hence, it was decided to implement this value at the present work. Their correlation for the grout thermal resistance was deduced for the general expression of offset cylinders from Holman (2010) as:

$$
\begin{aligned}
& R_{f}=\frac{1}{S_{f} k_{g}} \\
& S_{f}=\frac{2 \pi L}{\cosh ^{-1}\left\{\frac{D_{B}^{2}+d_{0}^{2}-S_{p}^{2}}{2 D_{B} d_{D}}\right\}}
\end{aligned}
$$

\section{Borehole Thermal Resistance}

The model presented here is a one dimensional heat transfer rate in the radial direction. The equivalent thermal resistance of the borehole of the single tubing represents the heat obstruction for the U-tube system in the form:

$$
\begin{aligned}
& R_{B}=R_{f}+R_{p} \\
& R_{B}=\frac{\ln \left(\frac{D_{B}}{d_{g}}\right)}{2 \pi k_{g}}+\frac{1}{\pi d_{i} h}+\frac{\ln \left(\frac{d_{o}}{d_{i}}\right)}{2 \pi k_{p}}
\end{aligned}
$$

\section{Total Thermal Resistance}

The tubing of the ground heat exchanger is subjected to a total thermal resistance to heat transfer defined as:

$$
\begin{aligned}
& R_{t}=R_{f}+R_{p}+R_{\text {ground }} \\
& R_{t}=\frac{\ln \left(\frac{D_{B}}{d_{g}}\right)}{2 \pi k_{g}}+\frac{1}{\pi d_{i} h}+\frac{\ln \left(\frac{d_{o}}{d_{i}}\right)}{2 \pi k_{p}}++R_{\text {ground }}
\end{aligned}
$$

The ground thermal resistance is presented as that of the soil surrounding the borehole resistance, which is a time dependent measure, Garbai and Méhes (2008).

\section{Case Study}

The objective is to provide a simple tool for the prediction of heat transfer rate rejected or absorbed by a ground single U-tube heat exchanger to perform heating or cooling demands. For the case where a DX geothermal heat pump system, the ground heat exchanger works as an evaporator or condenser for heating and cooling purposes respectively. For such cases, the following condition could be considered: 
1. During the condensation or evaporation processes, the change of phase takes place in an isothermal process for pure fluids and mixtures having negligible temperature glide.

2. Copper tubing is usually implemented for such purpose that has a high thermal conductivity to ensure easy way to heat flow through the tube wall.

3. One dimensional heat flow in the radial direction where a homogenous conditions present outside the U-tube.

4. The single equivalent tube possesses the thermal resistances as those of the U-tube for the convection of fluid flow and conduction of the tube wall.

5. Negligible influence of surface temperature fluctuations on the ground temperature.

6. Negligible thermal contact resistance between U-tube wall to grout and grout filling wall to the soil representing the constant temperature source or sink.

\section{Condensation Heat Transfer Coefficient}

Huang et al. (2010) have reported data for condensation of $R-410 \mathrm{~A} /$ oil mixture at mass flux density ranged between 200 to $600 \mathrm{~kg} / \mathrm{m}^{2} \mathrm{~s}$ and heat flux in the range of (4-19) $\mathrm{kW} / \mathrm{m}^{2}$. Their data showed a deterioration of condensation heat transfer coefficient with oil percent increase. The results showed that for condensation at $40{ }^{\circ} \mathrm{C}$, the heat transfer coefficient of pure $(R-410 A)$ was ranged between 2.4 to $4.6 \mathrm{~kW} / \mathrm{m}^{2}{ }^{\circ} \mathrm{C}$ for the test range of vapor quality between 0.2 and 0.9 and tube diameter of $5 \mathrm{~mm}$. Kim and Shin (2005) reported their experimental data for condensation heat transfer coefficient in $9.52 \mathrm{~mm}$ outside diameter at heat flux of $11 \mathrm{~kW} / \mathrm{m}^{2}$, condensation temperature of $45^{\circ} \mathrm{C}$, mass flux velocity of 273 to $287 \mathrm{~kg} / \mathrm{m}^{2} \mathrm{~s}$ and vapor quality of $(0.1-0.9)$. The data presented a range between 2 to $3 \mathrm{~kW} / \mathrm{m}^{2}{ }^{\circ} \mathrm{C}$ depending on vapor quality.

\section{Grout Thermal Conductivity}

Sagia et al. (2012) presented a tabulated list of the thermal conductivity of a number of grout mixtures as deduced from Gaia Geothermal (2009).

Table 2. Thermal Conductivity of Grout Mixtures, Gaia Geothermal (2009)

\begin{tabular}{|l|c|}
\hline \multicolumn{1}{|c|}{ Grouts } & $\begin{array}{c}\text { Thermal Conductivity } \\
\text { (W/m K) }\end{array}$ \\
\hline $20 \%$ Bentonite & 0.73 \\
\hline $30 \%$ Bentonite & 0.74 \\
\hline Cement Mortar & 0.78 \\
\hline Concrete $2100 \mathrm{~kg} / \mathrm{m}^{3}$ & 1.04 \\
\hline $30 \%$ Bentonite - 30\% Quartzite & 1.3 \\
\hline $30 \%$ Bentonite - 40\% Quartzite & 1.47 \\
\hline 60\% Quartzite- Flowable Fill (Cement+Fly & 1.85 \\
Ash+Sand) & \\
\hline Concrete (50\% Quartz Sand) & 1.9 \\
\hline
\end{tabular}


The range of grout thermal conductivity used in the industrial sector for fabrication of (GHE) as shown in Table 2 was used for the verification purpose of the present model.

\section{Copper Tubes}

The copper tubing diameter for the ground heat exchangers are usually selected in the range of (1/4-5/8) in. nominal or standard diameter of type (L) copper standards based on ASTM B88, Copper Development Association Inc. (2019). These sizes give outside diameters of (9.5-19.05) $\mathrm{mm}$ and inside diameters of $(8-16.9) \mathrm{mm}$ and wall factor of (12.5-17.86). Small tubing diameters are preferable for the (DX) ground heat exchangers to minimize the circulating refrigerant amount in the heat pump unit. The tube-bending radius of copper tubing is usually fabricated in the range of (2-3) times the outside diameter as a rule. Higher values are also possible depending on the available resources to accomplish the fabrication, Winton Machine Company (2019).

\section{Methodology}

Typical operating conditions were selected for comparison with existing models for the assessment of the thermal resistance of the ground heat exchanger (GHE). The following conditions were considered for the verification of the present work:

1- The condensation heat transfer coefficient for $R-410 A$ refrigerant is constant and fixed at $3000 \mathrm{~W} / \mathrm{m}^{2}{ }^{\circ} \mathrm{C}$ as a typical reference value deduced from Huang et al. (2010) and Kim and Shin (2005).

2- The copper U-tube has equal tube diameters for the descending and ascending fluid carrier legs. The respective dimensions of the test geometries are presented in Table 3.

Table 3. Dimensions of Test Geometry Configurations

\begin{tabular}{|l|c|c|c|c|c|c|}
\hline Geometry & $\mathbf{W F}$ & $\begin{array}{c}\mathbf{d}_{\mathbf{o}} \\
(\mathbf{m m})\end{array}$ & $\begin{array}{c}\mathbf{S}_{\mathbf{p}} \\
(\mathbf{m m})\end{array}$ & $\begin{array}{c}\mathbf{D}_{\mathbf{B}} \\
(\mathbf{m m})\end{array}$ & $\begin{array}{c}\mathbf{d}_{\mathbf{o}} / \mathbf{D}_{\mathbf{B}} \\
(---)\end{array}$ & $\begin{array}{c}\mathbf{S}_{\mathbf{p}} / \mathbf{D}_{\mathbf{B}} \\
(---)\end{array}$ \\
\hline 1 & 14.29 & 12.7 & 42 & 75 & 0.17 & 0.56 \\
\hline 2 & 15.63 & 15.875 & 55.6 & 90 & 0.18 & 0.62 \\
\hline 3 & 17.86 & 19.05 & 67 & 100 & 0.19 & 0.67 \\
\hline
\end{tabular}

\section{Results and Discussion}

\section{Grout Specific Thermal Resistance}

The comparison of grout specific thermal resistance with other correlations is presented in Figure 2 for all geometry configurations. The general trend of the 
behavior of the grout specific thermal resistance shows that it decreases with grout thermal conductivity increase and vice versa.

Figure 2. Comparison of the Grout Specific Thermal Resistance with Existing Models at Various Wall Factors

Figure 2a. Grout Specific Thermal Resistance at $W F=14.29$

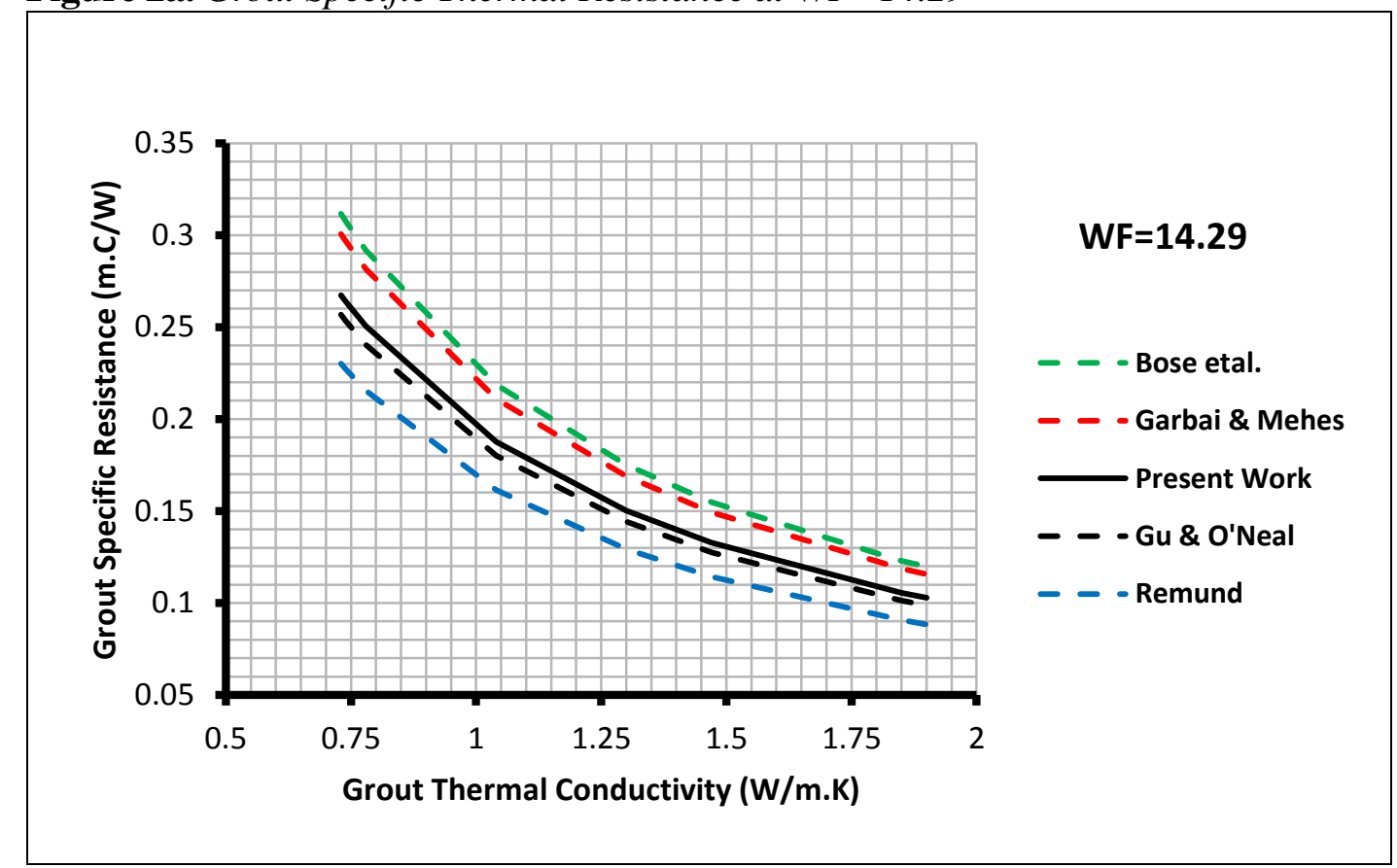

Figure 2b. Grout Specific Thermal Resistance at WF=15.63

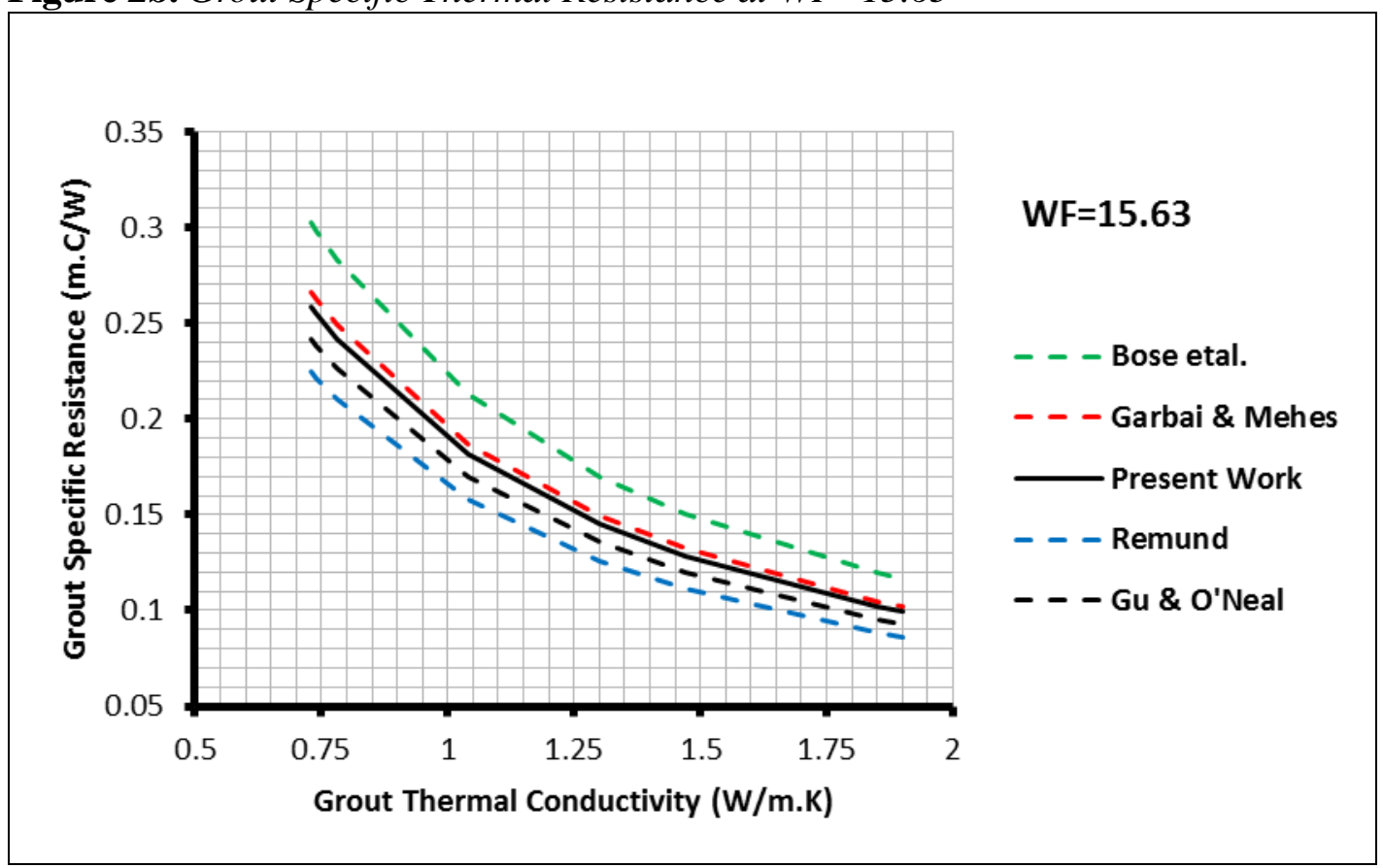


Figure 2c. Grout Specific Thermal Resistance at $W F=17.86$

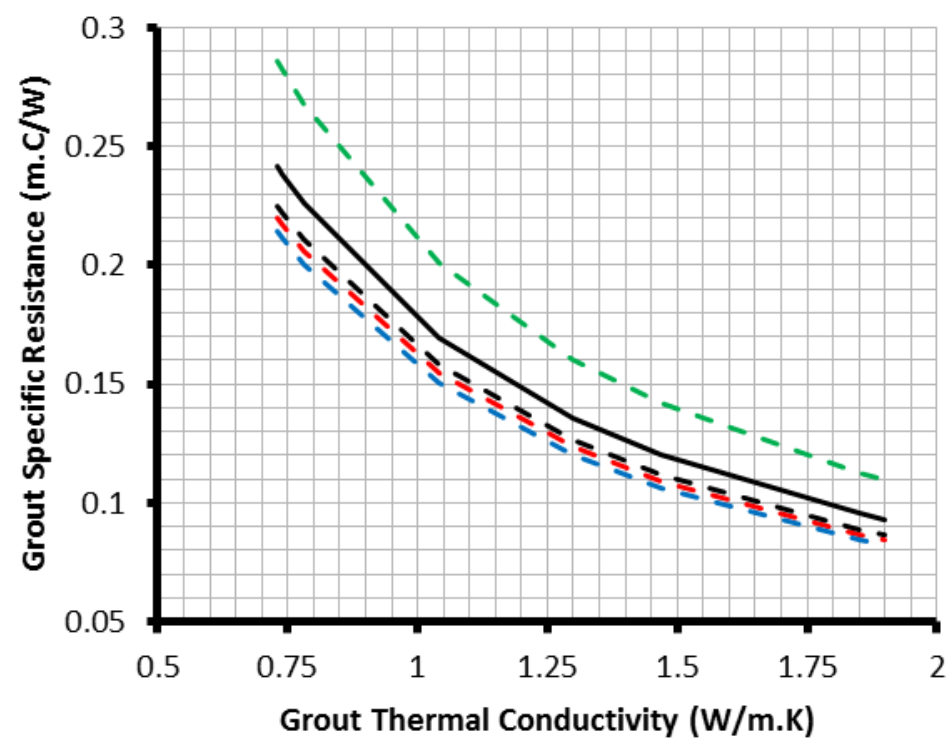

WF $=17.86$

- - - Bose etal.

- - - Garbai \& Mehes

—_ Present Work

- - - Remund

_ - - Gu \& O'Neal

For all tested geometries, Bose et al. (1985) correlation produced the highest thermal resistance among other models whereas Remund (1999) correlation revealed the lowest one; this was regardless of the tube geometry. The present model prediction occupied the middle zone bounded by those correlations as illustrated in Figure 2.

Equations (3, 4 and 16) show that these relations share the idea of using an equivalent diameter to represent the U-tube system centered at the borehole. Table 4 shows some of the calculated values for the geometry configurations considered by those equations for geometry (1).

Table 4. Geometrical Presentation of the Present Work and Other Investigators for $W F=14.29$

\begin{tabular}{|c|c|c|c|c|c|c|c|c|c|}
\hline Model & $\begin{array}{c}\mathbf{d}_{\mathbf{o}} \\
(\mathbf{m m})\end{array}$ & $\begin{array}{c}\mathbf{S}_{\mathbf{p}} \\
(\mathbf{m m})\end{array}$ & $\begin{array}{c}\mathbf{d}_{\mathbf{e}} \\
(\mathbf{m m})\end{array}$ & $\begin{array}{c}\mathbf{A}_{\mathbf{e}} \\
\left(\mathbf{m m}^{2} / \mathbf{m}\right)\end{array}$ & $\begin{array}{c}\mathbf{V}_{\mathbf{e}} \\
\left(\mathbf{m m}^{\mathbf{3}} / \mathbf{m}\right)\end{array}$ & $\begin{array}{c}\mathbf{A}_{\text {U-tube }} \\
\left(\mathbf{m m}^{2} / \mathbf{m}\right)\end{array}$ & $\begin{array}{c}\mathbf{V}_{\text {U-tube }} \\
\left(\mathbf{m m}^{\mathbf{3}} / \mathbf{m}\right)\end{array}$ & $\begin{array}{c}\mathbf{A}_{\text {red }} \\
(\mathbf{\%})\end{array}$ & $\begin{array}{c}\mathbf{V}_{\text {inc. }} \\
(\boldsymbol{\%})\end{array}$ \\
\hline $\begin{array}{c}\text { Gu and } \\
\text { O'Neal }\end{array}$ & 12.7 & 42 & 23.1 & 72.57 & 419.1 & 79.8 & 265 & 10 & 58.2 \\
\hline $\begin{array}{c}\text { Present } \\
\text { Work }\end{array}$ & 12.7 & 42 & 22 & 69.12 & 380.1 & 79.8 & 265 & 15.5 & 43.4 \\
\hline $\begin{array}{c}\text { Bose } \\
\text { et al. }\end{array}$ & 12.7 & 42 & 18.96 & 56.42 & 282.34 & 79.8 & 265 & 41.4 & 0 \\
\hline
\end{tabular}

The numerical values illustrate that the equivalent diameter predicted by Bose et al. (1985) was the lowest among other relations and hence higher thermal resistance. Their model was based implicitly on the assumption of using the fixed volume per unit length which was in effect caused a loss of heat transfer area by $41.4 \%$ compared to the present work and Gu \& O'Neal (1998). The latter showed the lower area reduction percent during the transformation to the single equivalent 
diameter, it was about $10 \%$ whereas the present work showed a reduction of 15.5 $\%$ for the equivalent surface area when compared to the original U-tube one.

This result emphasizes that regardless of the grout volume packed in the borehole, it will reach a steady state operation and has no significant effect on the process of heat transfer under the steady state condition. Whereas, the surface area of piping system represents the major factor which possesses the larger contribution influence on heat transfer rate through the borehole. This is since other sources of thermal resistances are time independent such as pipe, grout and ground resistance when approaches the steady state condition. The numerical values of the predicted thermal resistance of the present work for the test geometries are presented in Table 5 at grout thermal conductivity of $0.73 \mathrm{~W} / \mathrm{m} . \mathrm{K}$.

Table 5. Present Work Test Geometries and Predicted Thermal Resistance at Grout Thermal Conductivity of (0.73) W/m.K

\begin{tabular}{|l|c|c|c|c|c|c|c|}
\hline Geometry & $\mathbf{W F}$ & $\begin{array}{c}\mathbf{d}_{\mathbf{o}} \\
(\mathbf{m m})\end{array}$ & $\begin{array}{c}\mathbf{S}_{\mathbf{p}} \\
(\mathbf{m m})\end{array}$ & $\begin{array}{c}\mathbf{D}_{\mathbf{B}} \\
(\mathbf{m m})\end{array}$ & $\begin{array}{c}\mathbf{d}_{\mathbf{e}} \\
(\mathbf{m m})\end{array}$ & $\begin{array}{c}\mathbf{R}_{\mathbf{g}} \\
\left(\mathbf{m} .{ }^{\circ} \mathbf{C} / \mathbf{W}\right)\end{array}$ & $\begin{array}{c}\mathbf{R}_{\mathbf{t}} \\
\left(\mathbf{m} .{ }^{\circ} \mathbf{C} / \mathbf{W}\right)\end{array}$ \\
\hline 1 & 14.29 & 12.7 & 42 & 75 & 22 & 0.267 & 0.33 \\
\hline 2 & 15.63 & 15.875 & 55.6 & 90 & 27.5 & 0.259 & 0.32 \\
\hline 3 & 17.86 & 19.05 & 67 & 100 & 33 & 0.242 & 0.30 \\
\hline
\end{tabular}

The results for different geometries are compared to those predicted by $\mathrm{Gu}$ and O'Neal (1998) are illustrated in Figure 3. It is clear that these correlations predicted a similar data trend for the grout thermal resistance and close to each other in their numerical magnitudes.

Figure 3. Comparison of the Grout Specific Thermal Resistance with Gu and O’Neal Model at Various Borehole Geometry Configurations

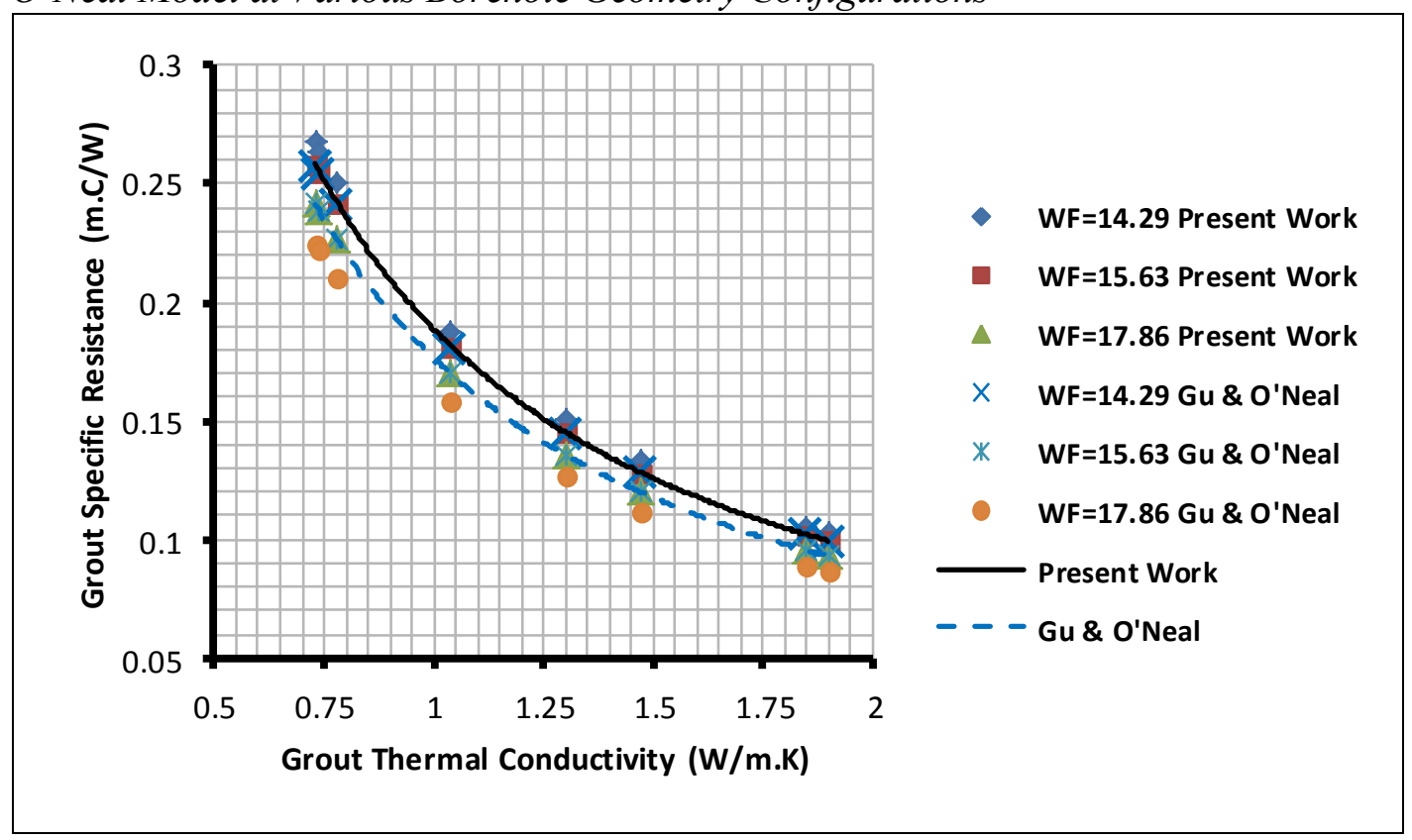


The general trend of the predicted grout thermal resistance is compared to other correlation in Figure 4.

Figure 4. Data Trend Comparison of Grout Specific Thermal Resistance for Various Geometry Configurations with Other Investigators

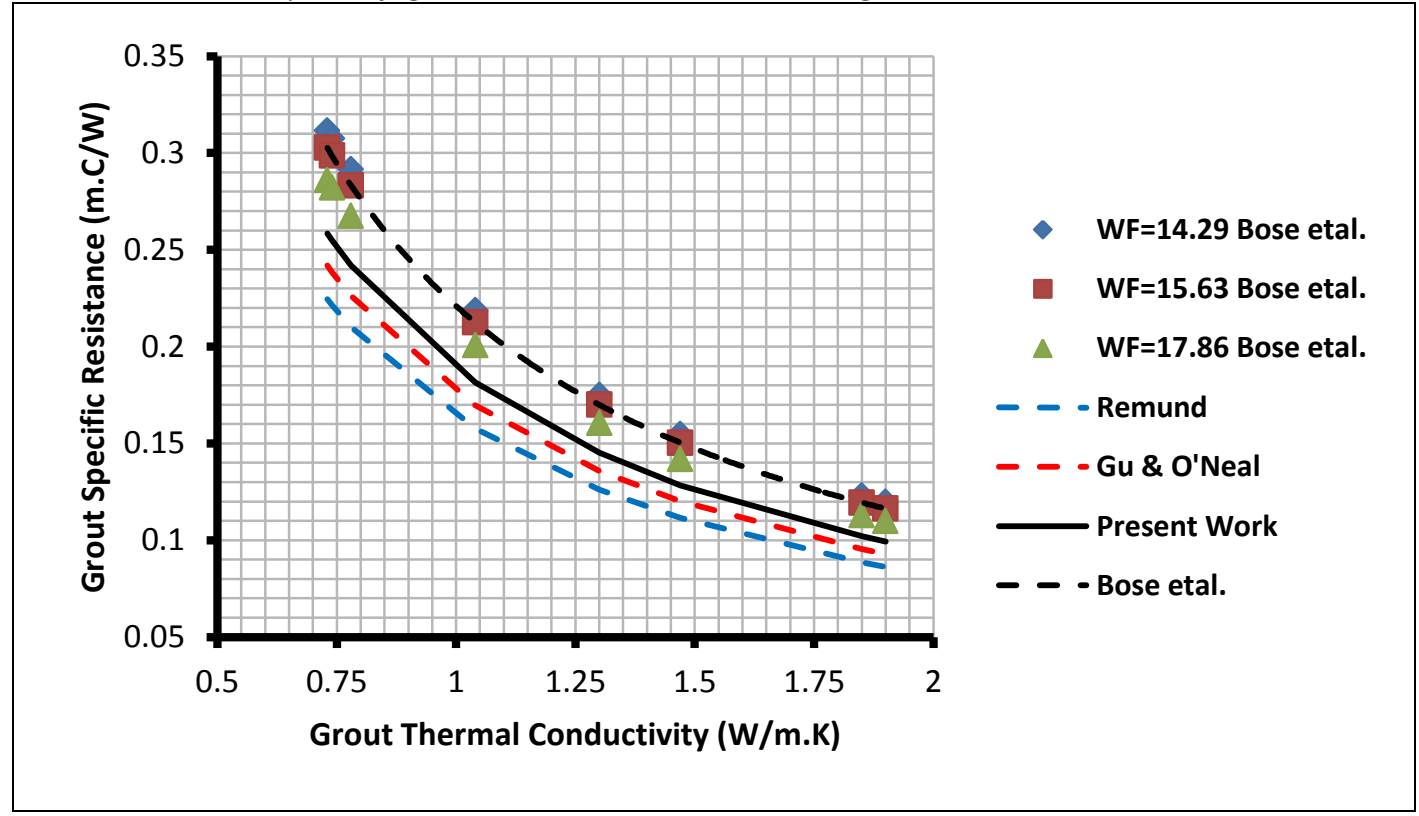

It is obvious that all models predict the same trend of data for the grout thermal resistance and showed a consistence with thermal conductivity of packing. The bigger tube size $\mathrm{WF}=17.86$ showed a lower grout thermal resistance, this is due to the reduction of grout layer with increasing of the tube diameter. This phenomenon was also confirmed by other investigators.

\section{Specific Total Thermal Resistance}

The developed correlations for the grout thermal resistance by Garbai and Méhes (2008), Bose et al. (1985), Gu and O’Neal (1998), and Remund (1999) were implemented in eq. (19) for comparison with the present work, Figure 5. The models developed by Bose et al. (1985) and Garbai and Méhes (2008) showed similar values of the thermal resistance predictions and were higher than those of the present work, Gu and O'Neal (1998) and Remund (1999) models, Figure 5a and 5b. They exhibited a deviation in the range of (10.6-13.3)\% and (21-28)\% higher than the present model and that of Remund (1999) respectively for $\mathrm{WF}=14.29$, Figure $5 \mathrm{a}$. The corresponding values at $\mathrm{WF}=15.63$ were $(10.6-13.8) \%$ and (20-27)\% higher than those of the present work and Remund (1999) respectively, Figure $5 \mathrm{~b}$. 
Vol. 7, No. 2

Tarrad: A Perspective Model for Borehole...

Figure 5. Comparison of the Present Work Specific Total Borehole Thermal Resistance with Existing Models at Various Values of Wall Factors

Figure 5a. Specific Total Resistance at $W F=14.29$

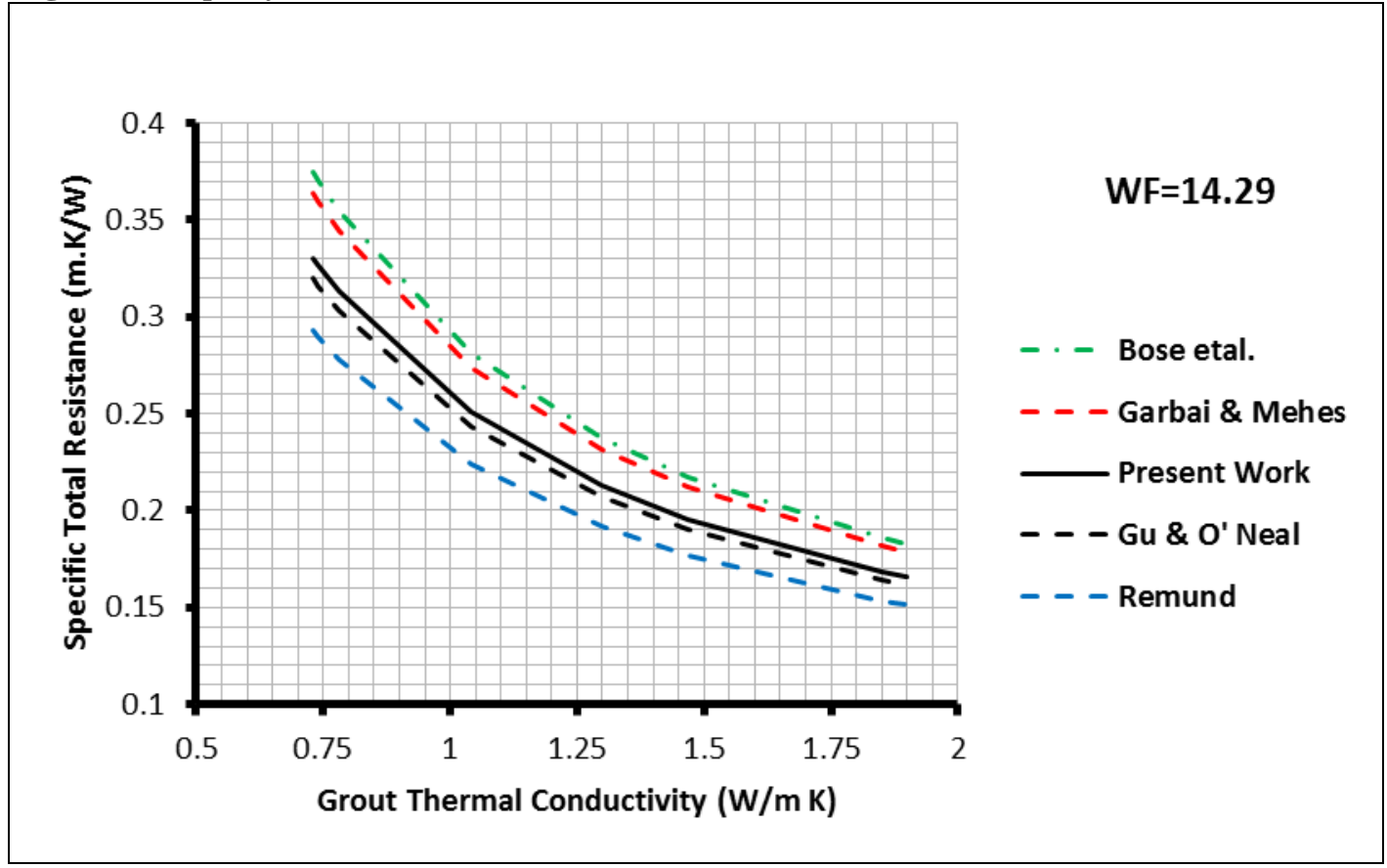

Figure 5b. Specific Total Resistance at $W F=15.63$

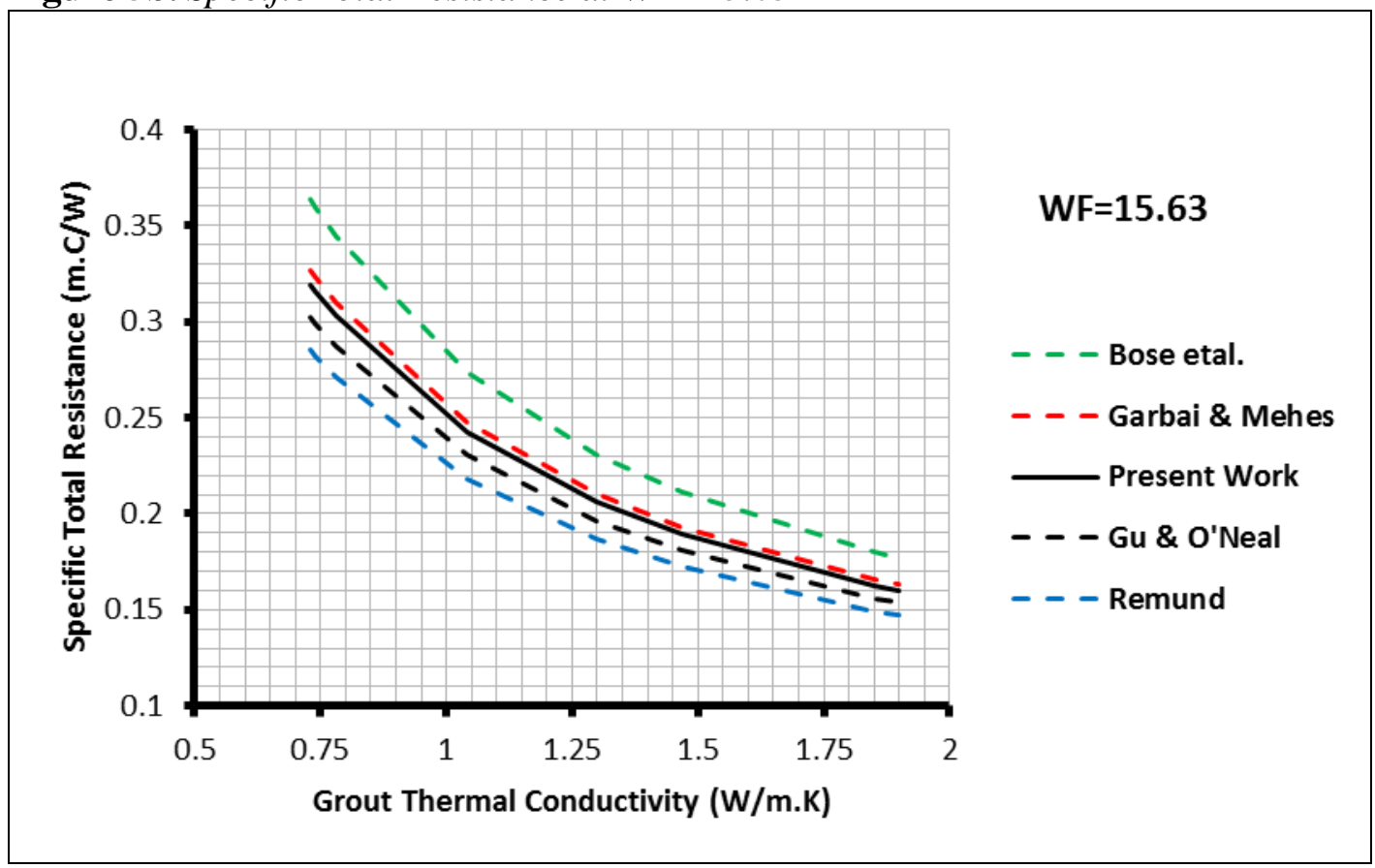


Figure 5c. Specific Total Resistance at $W F=17.86$

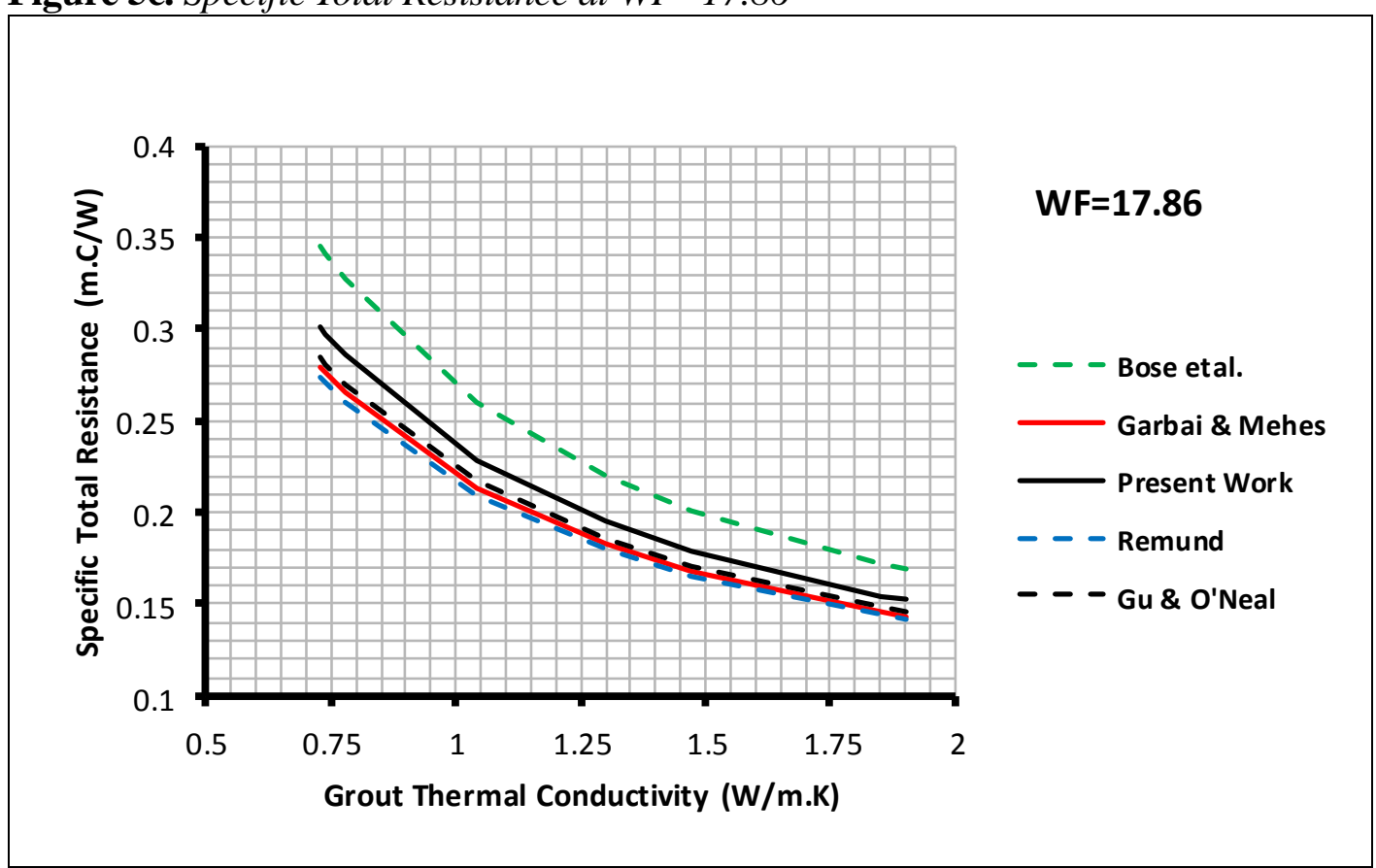

The other correlations predicted moderate values of total thermal resistances to be in the range of those predicted by Bose et al. (1985) and Remund (1999). The Gu and O'Neal (1998) correlation showed a closer thermal resistance than other correlation to the predicted values of the present work, Figure $5 \mathrm{a}$ and $5 \mathrm{~b}$. Moreover, the present work predicts exactly the same thermal resistance as that of $\mathrm{Gu}$ and O'Neal (1998) when the tube spacing of U-tube inside the borehole was selected as $\left(3 \mathrm{~d}_{\mathrm{o}}\right)$. Bose et al. (1985) correlation has also revealed higher values and Remund (1999) produced the lower resistance for geometry (3) but Garbai and Méhes model predicted almost similar values to those of Remund (1999).

The present work as other investigations has revealed the important role of the grout thermal conductivity on the overall thermal performance of the ground heat exchanger. The specific total thermal resistance of the heat exchanger was halved when $\left(k_{g}\right)$ was increased from $0.73 \mathrm{~W} / \mathrm{m} . \mathrm{K}$ to $1.9 \mathrm{~W} / \mathrm{m} . \mathrm{K}$ for all of the examined configurations as shown in Figure 5. Hence, the heat transfer rate to or from the ground source at the highest tested $\left(k_{g}\right)$ will be a double of that predicted at the lowest $\left(k_{g}\right)$ when the heat exchangers operate under the same conditions.

\section{Conclusions}

A model was postulated for the estimation of thermal resistance for a single U-tube ground-coupled heat pump implemented in the geothermal energy source. The equivalent diameter derivation technique showed a consistence with other published models. The grout thermal conductivity $\left(k_{g}\right)$ showed a high impact on the thermal performance of the borehole geometry. The minimum heat exchanger specific total thermal resistance $\left(R_{t}\right)$ was predicted at $\left(k_{g}\right)$ of $1.9 \mathrm{~W} / \mathrm{m} . \mathrm{K}$ for all of 
the investigated geometry configurations. Hence, the maximum heat transfer rate to or from the ground source is expected to be at the highest tested grout thermal conductivity. Increasing of $\left(k_{g}\right)$ from $0.73 \mathrm{~W} / \mathrm{m} . \mathrm{K}$ to $1.9 \mathrm{~W} / \mathrm{m} . \mathrm{K}$ has halved $\left(R_{t}\right)$ of the heat exchanger. The maximum $\left(R_{t}\right)$ was estimated at the smaller tube size/borehole geometry and $\left(k_{g}\right)$ of $0.73 \mathrm{~W} / \mathrm{m} . \mathrm{K}$, it fell within the range of $(0.3$ $0.33) \mathrm{m} .{ }^{\circ} \mathrm{C} / \mathrm{W}$. The heat conduction through the shunt $\left(\dot{Q}_{S}\right)$ between the legs of the U-tube vanishes for isothermal evaporation and condensation processes. The prediction of $\left(R_{t}\right)$ for the heat exchanger showed a good agreement with previous published models in the field. The outcome of this work could be used for a preliminary thermal design of ground source heat pump with acceptable confidence.

\section{Nomenclature}

$\begin{array}{ll}\text { Parameter } & \text { Definition } \\ A & \text { Surface area, } \mathrm{m}^{2} \\ d & \text { Diameter, } \mathrm{m} \\ D_{B} & \text { Borehole diameter, } \mathrm{m} \\ h & \text { Heat transfer coefficient, } \mathrm{W} / \mathrm{m}^{2} \mathrm{~K} \\ k & \text { Thermal conductivity, W/m.K } \\ L & \text { Tube length or borehole depth, } \mathrm{m} \\ P & \text { Perimeter of tube, } \mathrm{m} \\ \dot{Q} & \text { Heat transfer rate, } \mathrm{W} \\ r & \text { Radius, } \mathrm{m} \\ R & \text { Specific thermal resistance, } \mathrm{m} .{ }^{\circ} \mathrm{C} / \mathrm{W} \\ S & \text { Shape factor of cylindrical object, } \mathrm{m} \\ S_{p} & \text { Center to center tube spacing, } \mathrm{m} \\ t & \text { Tube thickness, } \mathrm{m} \\ \Delta T & \text { Temperature difference, } \mathrm{K} \\ U & \text { Overall heat transfer coefficient, } \mathrm{W} / \mathrm{m}^{2} \mathrm{~K} \\ V & \text { Volume of tube, } \mathrm{m}^{3} \\ W F & \text { Tube wall factor defined as }\left(d_{d} / t\right) \\ x & \text { A variable defined in eq. }(6 . \mathrm{b})\end{array}$

\section{Subscription}

$\begin{array}{ll}\text { B } & \text { Borehole } \\ e \text { end } & \text { Bending } \\ e & \text { Equivalent } \\ f & \text { Filling } \\ g & \text { Grout } \\ i & \text { Inside } \\ \text { in } & \text { Inlet port } \\ \text { inc. } & \text { Increase } \\ m & \text { Mean value }\end{array}$




$\begin{array}{ll}o & \text { Outside } \\ \text { out } & \text { Outlet port } \\ p & \text { Pipe value } \\ r e d & \text { Reduction } \\ s & \text { Shunt } \\ t & \text { Total }\end{array}$

\section{Greek Letters}

Coefficient defined in eq. (2)

\section{References}

Bose JE, Parker JD, McQuiston FC (1985) Design/data manual for closed-loop groundcoupled heat pump systems. Atlanta: American Society of Heating, Refrigeration and Air Conditioning Engineers (ASHRAE).

Carslaw HS, Jaeger JC (1959) Conduction of heat in solids. $2^{\text {nd }}$ Edition. London: Oxford University Press.

Claesson J, Dunand A (1983) Heat extraction from the ground by horizontal pipes - A mathematical analysis. Stockholm: Document D1, Swedish Council for Building Research.

Copper Development Association Inc. (2019) DX geothermal heating/cooling. Retrieved from: https://www.copper.org/applications/plumbing/apps/dx_gt_htg_clng.html. [Accessed 16 September 2019].

Fischer RD, Stickford GH (1983) Technical and economic feasibility of horizontal, multiple shallow-well and deep-well ground coupling. ORNUSub/80-78001 3\&06. Oak Ridge, Tennessee: Oak Ridge National Laboratory.

Gaia Geothermal (2009) Ground Loop Design Software. GLD.

Garbai L, Méhes S (2008) Heat capacity of vertical ground heat exchangers with single Utube installation in the function of time. WSEAS Transactions on Heat and Mass Transfer 3(3): 177-186.

Gu Y, O'Neal DL (1998) Development of an equivalent diameter expression for vertical U-tubes used in ground-coupled heat pumps. ASHRAE Transaction 104, part (2)4214: 1-9.

Hafiz MK, Birgitta JM, Erkki H (2017) Analysis of ground heat exchanger for a ground source heat pump: a study of an existing system to find optimal borehole length to enhance the coefficient of performance. WSEAS Transactions on Heat and Mass Transfer 12(Apr): 38-47.

Holman JP (2010) Heat transfer. 10 ${ }^{\text {th }}$ Edition. McGraw-Hill, 83-86.

Huang X, Ding G, Hu H, Zhu Y, Gao Y, Deng B (2010) Condensation heat transfer characteristics of R410A-oil mixture in $5 \mathrm{~mm}$ and $4 \mathrm{~mm}$ outside diameter horizontal microfin tubes. Experimental Thermal and Fluid Science 34(7): 845-856.

Ingersoll LR, Zobel OJ, Ingersoll AC (1948) Heat conduction with engineering and geological application. New York: McGraw Hill.

Ingersoll LR, Zobel OJ, Ingersoll AC (1954) Heat conduction with engineering, geological and other applications. Revised Edition. Madison: University of Wisconsin Press. 
Kavanaugh S (1985) Simulation and experimental verification of vertical ground coupled heat pump systems. PhD Thesis. USA: Oklahoma State University.

Kim M, Shin J (2005) Condensation heat transfer of R-22 and R410A in horizontal smooth and microfin tubes. International Journal of Refrigeration 28(6): 949-957.

Mei VC, Baxter VD (1986) Performance of a ground coupled heat pump with multiple dissimilar U-tube coils in series. ASHRAE Transactions 92(2A): 30-42.

Muttil N, Chau KW (2006) Neural network and genetic programming for modeling coastal algal blooms. International Journal of Environment and Pollution 28(3/4): 223-238.

Remund CP (1999) Borehole thermal resistance: laboratory and field studies. ASHRAE Transactions 105: 439-445.

Sagia Z, Stegou A, Rakopoulos C (2012) Borehole resistance and heat conduction around vertical ground heat exchangers. The Open Chemical Engineering Journal 6(1): 3240.

Sharqawy MH, Mokheimer EM, Badr HM (2009) Effective pipe-to-borehole thermal resistance for vertical ground heat exchangers. Geothermics 38(2): 271-277.

Tarrad AH (2019) A borehole thermal resistance correlation for a single vertical DX Utube in geothermal energy application. American Journal of Environmental Science and Engineering 3(4): 75-83.

Winton Machine Company (2019) Tips for bending small diameter copper tubing with a CNC machine. Retrieved from: https://www.wintonmachine.com/tips-for-bendingsmall-diameter-copper-tubing/. [Accessed 15 September 2019].

Zeng H, Diao N, Fang Z (2003) Heat transfer analysis of boreholes in vertical ground heat exchangers. International Journal of Heat and Mass Transfer 46(23): 4467-4481.

Zhu L, Chen S, Yang Y, Sun Y (2019) Transient heat transfer performance of a vertical double U-tube borehole heat exchanger under different operation conditions. Renewable Energy 131(Feb): 494-505. 